Med Clin North Am. 2020 November ; 104(6): 1051-1062. doi:10.1016/j.mcna.2020.08.007.

\title{
Screening for Prostate Cancer
}

\author{
Sigrid V. Carlsson, MD, PhD, MPH ${ }^{1,2,3}$, Andrew J. Vickers, PhD $^{2}$ \\ ${ }^{1}$ Department of Surgery (Urology Service), Memorial Sloan Kettering Cancer Center, New York, \\ NY, USA. \\ ${ }^{2}$ Department of Epidemiology and Biostatistics, Memorial Sloan Kettering Cancer Center, New \\ York, NY, USA. \\ ${ }^{3}$ Department of Urology, Institute of Clinical Sciences, Sahlgrenska Academy at University of \\ Gothenburg, Sweden
}

\section{Keywords}

Prostate cancer; screening; prostate-specific antigen; biomarkers; magnetic resonance imaging

\section{Introduction}

\section{Epidemiology}

Prostate cancer is a major public health problem across the globe. With 1.3 million new cases and 359,000 deaths in 2018, prostate cancer is the second most common cancer and the fifth leading cause of cancer death in men worldwide. It is the commonest cancer in men in more than half of the countries of the world (105 of 185) and the leading cause of cancer death in men in 46 countries. The highest rates are seen in the Caribbean. Prostate cancer mortality has been decreasing in many countries due to screening, early detection and improved treatment (e.g., Northern America, Northern and Western Europe, Oceania and developed countries of Asia) but increasing in several countries (e.g., Central and South America, Central and Eastern European countries, many countries in Asia) possibly due to changes in risk factors, a more Westernized life style and limited access to treatment. ${ }^{1}$

\section{Current evidence for prostate cancer screening}

Localized prostate cancer is asymptomatic. By the time symptoms become present, the disease is generally too advanced for cure. Indeed, one of the most common presentations of

\footnotetext{
Corresponding author: Andrew J. Vickers, PhD, Memorial Sloan Kettering Cancer Center, Department of Epidemiology and Biostatistics, 485 Lexington Avenue, New York, NY, 10065, USA, vickersa@ mskcc.org.

Publisher's Disclaimer: This is a PDF file of an unedited manuscript that has been accepted for publication. As a service to our customers we are providing this early version of the manuscript. The manuscript will undergo copyediting, typesetting, and review of the resulting proof before it is published in its final form. Please note that during the production process errors may be discovered which could affect the content, and all legal disclaimers that apply to the journal pertain.

Disclosure Statement

Andrew J. Vickers is named on a patent for a statistical method to detect prostate cancer. The patent application for the statistical model has been licensed and commercialized as the 4 Kscore by OPKO Diagnostics. Andrew J. Vickers receives royalties from sales of this test and owns stock options in OPKO.
} 
prostate cancer before the advent of screening was paralysis, related to spinal cord metastasis. Therefore, the concept of screening is particularly appealing for prostate cancer, as it provides an opportunity to identify the disease at a curable stage. This called for a test that could detect prostate cancer earlier, and led to the discoveries of the blood test prostatespecific antigen (PSA), first isolated and defined in the 1970's. ${ }^{2-4}$ Several screening studies in the late 80's-early 90's showed that the PSA-test could identify more prostate cancers at an organ-confined, clinically localized stage as compared to evaluations for palpable tumors by digital rectal examination, which set the stage for a widespread adoption of PSA-testing, particularly in the U.S. This resulted in a rapid surge in prostate cancer incidence. ${ }^{5-10}$

There is level 1 evidence for PSA-screening from large-scale randomized controlled trials, comparing regular PSA-screening of men ages 50-70 every 2-4 years to no invitation to screening. The European Randomized Study of Screening for Prostate Cancer (ERSPC) reports a reduction in prostate cancer mortality by $20 \%$ (rate ratio [RR] 0.80 , 95\% CI 0.72 $0.89, \mathrm{p}<0.001$ ) at 16 years of follow-up in favor of screening. ${ }^{11}$ At this follow-up, the number needed to invite to screening to prevent one prostate cancer death is reported to be 570 and the number needed to diagnose is 18 . The corresponding estimates from the Swedish Göteborg-1 trial with 18 years of follow up are a reduction in prostate cancer mortality of $35 \%$ (RR $0.65,95 \%$ CI $0.49-0.87, \mathrm{p}=0.003$ ). To prevent one death from prostate cancer at 18 years, the number needed to invite to screening was 231 and the number needed to diagnose was 10. In contrast, at 17 years of follow-up in the U.S. Prostate, Lung, Colorectal and Ovarian (PLCO) Cancer Screening Trial, there was no significant difference in prostate cancer mortality between the screening arm compared with the usual care arm (RR 0.93, 95\% CI 0.81-1.08, $\mathrm{p}=0.4) .{ }^{12}$ However, this has been attributed to a high degree of contamination of PSA-testing in the usual care arm, with over $50 \%$ of patients randomized to no screening nonetheless undergoing PSA testing. ${ }^{13,14}$ Statistical models have been used to reconcile the differences in implementation and settings and have reported that both trials provide compatible evidence that screening reduces prostate cancer mortality: estimated at 25\%-31\% in ERSPC and 27\%-32\% in PLCO, respectively. ${ }^{15}$ Similarly, there is welldocumented evidence from large, prospective observational studies regarding the prognostic utility of measuring a man's baseline PSA-level in midlife to determine subsequent risk of future life-threatening prostate cancer. ${ }^{16-21}$

The age-specific prostate cancer mortality in the U.S. is down by $50 \%$ from peak rates due to PSA screening and improvements in treatment, but recently this trend has been flattening due to recommendations against PSA screening in previous years, mainly the 2012 United States Preventive Services Task Force (USPSTF) guideline. ${ }^{10,22}$ Studies now document an increase in metastatic prostate cancer. ${ }^{23-26}$

\section{Controversies}

PSA screening can have several beneficial effects. Most men have a "normal" PSA value below the cut-off for further evaluation and up to $97 \%$ of men report some reassurance with PSA screening. ${ }^{27}$ Screening can reduce a man's risk of developing metastatic prostate cancer and dying from the disease. ${ }^{11,28}$ For every prevented death from prostate cancer, a life is lengthened by 8 years on average. ${ }^{29}$ 
However, screening can also induce many undesired effects including anxiety from false positive PSA-tests and complications from further investigation with prostate biopsy including hospitalization for infectious complications or rectal bleeding. ${ }^{30}$ One major harm of PSA screening is overdiagnosis, that is the diagnosis of indolent, slow-growing prostate cancer that would otherwise not be diagnosed during the man's lifetime. ${ }^{31-33}$ Indolent disease is typically defined in terms of cancer grade. Gleason Score 6, also termed Grade Group 1, is low-grade cancer that does not require immediate treatment. ${ }^{34}$ High-grade disease, for which treatment should be considered, is defined as Gleason Score 7 (Grade Group 2) or higher. Overdiagnosis turns healthy men into patients which may take its toll on psychological well-being and quality-of-life. ${ }^{35,36}$ Most importantly, over the past two decades, most men with low risk prostate cancer in the US underwent treatment with surgery and radiation. Such overtreatment has no, or almost no, benefit in terms of mortality reduction but leads to important and persistent side-effects, most notably, urinary and erectile dysfunction. ${ }^{37}$ In recent years there has been a large shift in the treatment trends with over half of men with low risk disease now being recommended so called active surveillance as the first management option, i.e., careful monitoring with repeated testing and examinations and a switch to curative treatment upon signs of disease progression. ${ }^{38-40}$ Avoiding overtreatment of indolent prostate cancer is crucial since active treatment with surgery, radiation or ablative focal therapies can have significant impact on men's quality-oflife. Many years after treatment with radical prostatectomy or radiotherapy for favorable-risk prostate cancer, significant deterioration still persists in a substantial proportion of men in one or many functional domains: sexual function, urinary function (incontinence) and bowel function. ${ }^{37,41}$ Modeling the lifetime effects of annual PSA-screening between ages 55-69 vs. no screening, Heijnsdijk and colleagues estimated a loss of $23 \%$ of life-years gained with screening, primarily due to impaired quality-of-life owing to long-term side-effects from treatment. $^{29}$

\section{Current guidelines}

Table 1 gives a summary of examples of current PSA screening recommendations from major guideline groups in the US and Europe. The guidelines are consistent in recommending shared decision-making before starting screening and that the age range for screening should be around $45-70$. There is some minor variation in the starting age (4555 ) and the criteria for an upper age limit. The proposal for screening outlined in the clinical care points below is based on the Memorial Sloan Kettering Cancer Center recommendations ${ }^{42}$ but are close to those of other groups.

\section{Clinical Care points}

Below, we propose seven steps for primary care doctors ${ }^{42,43}$ (Figure 1). Our proposal is based on the following principles. First, primary care is time-pressured and primary care physicians cannot be expected to have in-depth sub-specialty knowledge. Hence, our goal is to make shared decision-making and the subsequent screening algorithm relatively simple. Second, ensuring that PSA screening does more good than harm is primarily a matter of making sure that it does less harm: our recommendations reflect a "harm reduction" approach. Third, given that there is great variability within urology with respect to 
compliance with clinical practice guidelines, we do make it incumbent upon primary care physicians to check that any urologists to whom they refer patients are engaging in best practices (described in points 5, 6 and 7 below).

\section{Get consent for prostate cancer screening, preferably using the "Simple Schema" decision aid.}

Prostate cancer screening is a preference-sensitive decision with important consequences. As such, it is important to obtain informed consent from patients following shared decisionmaking. Although this only generally needs to occur once - informed consent is required to enter into a screening regimen, not for each and every PSA test - there are valid concerns as to the time required given the constraints of a busy primary care practice. Some guidelines recommend practices that are difficult to implement, such as one where patients are informed about 16 separate facts on PSA and are asked 12 questions about their preferences ${ }^{44}$. We developed what is known as the "Simple Schema"45 (Figure 2) for primary care physicians, which does not require knowledge above and beyond what any primary care physician would be expected to know, is brief and focuses on harm reduction. The critical step is to warn patients about the risk that PSA screening will lead to the identification of low-risk disease and the need to avoid aggressive treatment in such cases. Early emphasis on active surveillance as the optimal management strategy for low-risk disease is critical.

A common question amongst primary care physicians is whether they should more strongly endorse PSA screening for men at higher risk, such as African Americans, or those with a family history or a genetic disposition. In brief, there is no reason to believe that the benefitto-harm ratio of PSA screening varies sufficiently for higher risk groups to mandate screening. Moreover, attempts to tailor PSA screening based on genomic risk, what are known as "polygenic risk scores", have not shown clinical utility for population-based screening. ${ }^{46-49}$

\section{PSA screening is only for healthy men age $\mathbf{4 5}$ to $\mathbf{7 0 .}$}

It is widely known that the introduction of PSA screening has led to widespread overdiagnosis. What is less widely recognized is that overdiagnosis is highly age-dependent. Indeed, nearly half of the overdiagnosis associated with the introduction of PSA testing occurred in men aged over $70^{50}$. Critically, PSA testing is of doubtful value in men aged over 70: the hazard ratio for prostate cancer mortality for men over 70 reported by the ERSPC is 1.18 (95\% C.I. $0.81-1.72$ ), that is, likely no benefit and, at most, about a $20 \%$ reduction in the risk of death from prostate cancer ${ }^{51}$. Hence stopping screening at 70 will have a large effect on overdiagnosis with little, if any, effect on mortality. Note that by ceasing screening, we mean that PSA tests are generally discouraged in an asymptomatic man above 70 with PSA levels in the normal range (i.e. $<3 \mathrm{ng} / \mathrm{mL}$ ). Follow-up of older men above 70 with PSA levels above $3 \mathrm{ng} / \mathrm{mL}$ is a matter of clinical judgement, taking into account the age and general health of the man (denoted "PSA surveillance") ${ }^{52}$. Note also that it is reasonable to cease screening earlier that 70 for men who have important comorbidities or to continue screening in a 70 year-old in exceptional health. 
As regards the starting age for screening, it has been shown at age 45, but not before, it is possible to identify a subgroup of men who are at important risk of prostate cancer morbidity or mortality within 10 years. ${ }^{21}$ The yield is relatively low, that is, very few young men have an elevated PSA, and some commentators have therefore made the reasonable suggestion that screening start at 50 instead, based on this being the lowest age included in the ERSPC randomized trial. On the other hand, because younger men have a longer lifeexpectancy, they will lose a greater number of quality-adjusted life years from cancer-related death and are at low risk for overdiagnosis. It has also been shown that, because PSA is a far stronger predictor of prostate cancer specific mortality than race or family history, age at the start of screening should be the same for essentially all men ${ }^{53}$.

\section{Tailor screening frequency based on PSA-level and cease screening for men over 60 unless PSA is above median $(1 \mathrm{ng} / \mathrm{mL})$.}

PSA is not only diagnostic of the current risk of prostate cancer but highly prognostic of future risk. ${ }^{16-21}$ Moreover, because prostate cancer is generally slow growing, screening intervals can safely be extended for men with low PSA. There are clear data that men with a low PSA are highly unlikely to develop aggressive prostate cancer within an 8 to 10 year period $^{20,21,54}$. This has led to the "traffic light" algorithm as follows ${ }^{42}$ :

- $\quad$ PSA $<1 \mathrm{ng} / \mathrm{mL}$ : green light. Repeat PSA at 8 - 10 year interval.

- $\quad$ PSA $1-2.99$ ng/mL: amber light: Repeat PSA at a $2-4$ year interval.

- $\quad$ PSA $\geq 3 \mathrm{ng} / \mathrm{mL}$ : red light. Consider further work up.

Fully $90 \%$ of prostate cancer deaths by age 85 occur in men with PSA above the median of 1 $\mathrm{ng} / \mathrm{mL}$ at age $60^{20}$. It has also been shown that men with low PSA who continue to get screened are at some risk of overdiagnosis but receive no mortality benefit compared to if they had ceased screening. ${ }^{17,54}$ Hence men with PSA $<1 \mathrm{ng} / \mathrm{mL}$ at age 60 should cease screening.

\section{For men with elevated PSA ( $\geq 3 \mathrm{ng} / \mathrm{mL}$ ), repeat PSA.}

Many men will experience a temporary rise in PSA related to benign disease. For instance, in a landmark JAMA paper, $44 \%$ of men with PSA $>4$ and $40 \%$ of those with PSA $>2.5$ returned to normal PSA within 1 year. ${ }^{55}$ A typical recommendation is that PSA should be repeated 4-6 weeks later.

\section{Use secondary tests such as marker or imaging before biopsy or only refer to urologists who do so.}

Only a small proportion of men with a moderately elevated PSA will have the sort of highgrade prostate cancer that is important to identify. Typically, for every 100 men with PSA > $3 \mathrm{ng} / \mathrm{mL}$, approximately $70 \%, 20 \%$ and $10 \%$ respectively will have benign disease, lowgrade (indolent) prostate cancer and high-grade cancer. There are now a wide variety of secondary tests that are available to determine which men with an elevated PSA should be subject to prostate biopsy. These secondary tests, which include biomarkers as shown in Table 2, as well as multiparametric Magnetic Resonance Imaging (MRI), have been shown to reduce both unnecessary biopsies and overdiagnosis of indolent disease ${ }^{56-58}$. 
Some of these tests can be implemented in the primary care setting. For example, BioReference Laboratories offers a combined test for PSA, that is, when a PSA test is selected, the blood sample is automatically checked for the 4Kscore if PSA is elevated. However, in most cases, secondary tests are ordered by the urologist. This is obviously particularly true of MRI. As such, it is incumbent on the primary care physician to develop a relationship with a urologist who takes a conservative approach to biopsy, incorporating secondary tests and only conducting biopsy on men shown to be at elevated risk of highgrade prostate cancer.

\section{Only refer to urologists who recommend active surveillance to almost all patients with low-grade cancer.}

The major harm of PSA screening is overtreatment, with consequent urinary, sexual and bowel dysfunction ${ }^{37}$. Guidelines suggest that treatment should be restricted to men with high-grade disease. Men with Gleason Score 6 (Grade Group 1) cancer should be managed conservatively, with an approach known as active surveillance, which involves PSA monitoring, repeat biopsies at regular intervals and delayed intervention for men who progress to Grade Group 2 or higher disease. However, rates of active surveillance vary enormously between different practices: in one study, the proportion of low risk men placed on active surveillance ranged from $25 \%$ to $80 \%^{59}$. As a result, the urologist chosen by the primary care physician, must not only take a conservative approach to biopsy but a conservative approach to treatment. The primary care physician needs to ensure that the urologist raises active surveillance before biopsy and advises active surveillance to all, or nearly all, men with Gleason Score 6 (Grade Group 1) disease.

\section{Preferably refer to urologists at major academic centers.}

The volume-outcome relationship is one of the most widely replicated findings in cancer medicine. In brief, both the chance of cure and the chance of side-effects is strongly correlated with provider volume. ${ }^{60-63}$ In one study, the risk of recurrence after prostate cancer was approximately half as great for surgeons with 250 radical prostatectomies compared to those who only had experience of 10 prior cases ${ }^{64}$. As such, primary care physicians should recommend to patients who require treatment for their prostate cancer patients with Grade Group 2 or higher disease - should be treated at a high-volume center. The easiest way to ensure this is to refer patients to a hospital that is designated by the National Cancer Institute as a Comprehensive Cancer Center (https://www.cancer.gov/ research/nci-role/cancer-centers).

\section{Summary}

PSA screening can importantly reduce the risk of death from prostate cancer but is also associated with major harms, overdiagnosis and overtreatment, with attendant urinary, sexual and bowel dysfunction. Following a few simple steps can dramatically reduce the risk of harm from PSA screening without materially reducing its benefits. In particular, patients need to be informed repeatedly of the need for conservative management of low-grade prostate cancer and referred to urologists who promote active surveillance. Primary care 
physicians need to develop relationships with urologists who advocate conservative approaches to biopsy and treatment.

\section{Funding}

S.V.C.'s and A.J.V.'s work was supported in part by funding from National Institutes of Health/National Cancer Institute (P30 CA008748, P50 CA92629, U01 CA199338-02), the Prevent Cancer Foundation, and Sidney Kimmel Center for Prostate and Urologic Cancers. S.V.C. is also funded by a National Institutes of Health/National Cancer Institute Transition Career Development Award (K22 CA234400).

\section{References}

1. Bray F, Ferlay J, Soerjomataram I, Siegel RL, Torre LA, Jemal A. Global cancer statistics 2018: GLOBOCAN estimates of incidence and mortality worldwide for 36 cancers in 185 countries. CA: a cancer journal for clinicians. 2018;68(6):394-424. [PubMed: 30207593]

2. Wang MC, Valenzuela LA, Murphy GP, Chu TM. Purification of a human prostate specific antigen. Invest Urol. 1979;17(2):159-163. [PubMed: 89106]

3. Hara M, Koyanagi Y, Inoue T, Fukuyama T. [Some physico-chemical characteristics of “ seminoprotein", an antigenic component specific for human seminal plasma. Forensic immunological study of body fluids and secretion. VII]. Nihon Hoigaku Zasshi. 1971;25(4):322324. [PubMed: 5106556]

4. Li TS, Beling CG. Isolation and characterization of two specific antigens of human seminal plasma. Fertil Steril. 1973;24(2):134-144. [PubMed: 4631694]

5. Stamey TA, Yang N, Hay AR, McNeal JE, Freiha FS, Redwine E. Prostate-specific antigen as a serum marker for adenocarcinoma of the prostate. N Engl J Med. 1987;317(15):909-916. [PubMed: 2442609]

6. Catalona WJ, Smith DS, Ratliff TL, et al. Measurement of prostate-specific antigen in serum as a screening test for prostate cancer. The New England journal of medicine. 1991;324(17):1156-1161. [PubMed: 1707140]

7. Wang TY, Kawaguchi TP. Preliminary evaluation of measurement of serum prostate-specific antigen level in detection of prostate cancer. Ann Clin Lab Sci. 1986;16(6):461-466. [PubMed: 3800301]

8. Cooner WH, Mosley BR, Rutherford CL Jr., et al. Prostate cancer detection in a clinical urological practice by ultrasonography, digital rectal examination and prostate specific antigen. The Journal of urology. 1990;143(6):1146-1152; discussion 1152-1144. [PubMed: 1692885]

9. Brawer MK, Chetner MP, Beatie J, Buchner DM, Vessella RL, Lange PH. Screening for prostatic carcinoma with prostate specific antigen. The Journal of urology. 1992;147(3 Pt 2):841-845. [PubMed: 1371559]

10. Siegel RL, Miller KD, Jemal A. Cancer statistics, 2019. CA Cancer J Clin. 2019;69(1):7-34. [PubMed: 30620402]

11. Hugosson J, Roobol MJ, Mansson M, et al. A 16-yr Follow-up of the European Randomized study of Screening for Prostate Cancer. European urology. 2019.

12. Pinsky PF, Miller E, Prorok P, Grubb R, Crawford ED, Andriole G. Extended follow-up for prostate cancer incidence and mortality among participants in the Prostate, Lung, Colorectal and Ovarian randomized cancer screening trial. BJU international. 2018.

13. Shoag JE, Mittal S, Hu JC. Reevaluating PSA Testing Rates in the PLCO Trial. N Engl J Med. 2016;374(18):1795-1796. [PubMed: 27144870]

14. Pinsky PF, Blacka A, Kramer BS, Miller A, Prorok PC, Berg C. Assessing contamination and compliance in the prostate component of the Prostate, Lung, Colorectal, and Ovarian (PLCO) Cancer Screening Trial. Clinical trials. 2010;7(4):303-311. [PubMed: 20571134]

15. Tsodikov A, Gulati R, Heijnsdijk EAM, et al. Reconciling the Effects of Screening on Prostate Cancer Mortality in the ERSPC and PLCO Trials. Ann Intern Med. 2017;167(7):449-455. [PubMed: 28869989]

16. Vertosick EA, Haggstrom C, Sjoberg DD, et al. Prespecified Four Kallikrein Marker Model (4Kscore) at Age 50 or 60 for Early Detection of Lethal Prostate Cancer in a Large Population- 
Based Cohort of Asymptomatic Men Followed for 20 Years. The Journal of urology. 2020:101097JU0000000000001007.

17. Kovac E, Carlsson SV, Lilja H, et al. Association of Baseline Prostate-Specific Antigen Level With Long-term Diagnosis of Clinically Significant Prostate Cancer Among Patients Aged 55 to 60 Years: A Secondary Analysis of a Cohort in the Prostate, Lung, Colorectal, and Ovarian (PLCO) Cancer Screening Trial. JAMA Netw Open. 2020;3(1):e1919284. [PubMed: 31940039]

18. Preston MA, Gerke T, Carlsson SV, et al. Baseline Prostate-specific Antigen Level in Midlife and Aggressive Prostate Cancer in Black Men. European urology. 2019;75(3):399-407. [PubMed: 30237027]

19. Preston MA, Batista JL, Wilson KM, et al. Baseline Prostate-Specific Antigen Levels in Midlife Predict Lethal Prostate Cancer. Journal of clinical oncology : official journal of the American Society of Clinical Oncology. 2016;34(23):2705-2711. [PubMed: 27298404]

20. Vickers AJ, Cronin AM, Bjork T, et al. Prostate specific antigen concentration at age 60 and death or metastasis from prostate cancer: case-control study. BMJ. 2010;341:c4521. [PubMed: 20843935]

21. Vickers AJ, Ulmert D, Sjoberg DD, et al. Strategy for detection of prostate cancer based on relation between prostate specific antigen at age 40-55 and long term risk of metastasis: case-control study. BMJ (Clinical research ed). 2013;346:f2023.

22. Moyer VA. Screening for prostate cancer: U.S. Preventive Services Task Force recommendation statement. Ann Intern Med. 2012;157(2):120-134. [PubMed: 22801674]

23. Fleshner K, Carlsson SV, Roobol MJ. The effect of the USPSTF PSA screening recommendation on prostate cancer incidence patterns in the USA. Nat Rev Urol. 2017;14(1):26-37. [PubMed: 27995937]

24. Kelly SP, Anderson WF, Rosenberg PS, Cook MB. Past, Current, and Future Incidence Rates and Burden of Metastatic Prostate Cancer in the United States. Eur Urol Focus. 2018;4(1):121-127. [PubMed: 29162421]

25. Dalela D, Sun M, Diaz M, et al. Contemporary Trends in the Incidence of Metastatic Prostate Cancer Among US Men: Results from Nationwide Analyses. Eur Urol Focus. 2019;5(1):77-80. [PubMed: 28753893]

26. Bandini M, Mazzone E, Preisser F, et al. Increase in the Annual Rate of Newly Diagnosed Metastatic Prostate Cancer: A Contemporary Analysis of the Surveillance, Epidemiology and End Results Database. Eur Urol Oncol. 2018;1(4):314-320. [PubMed: 31100253]

27. Cantor SB, Volk RJ, Cass AR, Gilani J, Spann SJ. Psychological benefits of prostate cancer screening: the role of reassurance. Health expectations : an international journal of public participation in health care and health policy. 2002;5(2):104-113. [PubMed: 12031051]

28. Buzzoni C, Auvinen A, Roobol MJ, et al. Metastatic Prostate Cancer Incidence and Prostatespecific Antigen Testing: New Insights from the European Randomized Study of Screening for Prostate Cancer. European urology. 2015;68(5):885-890. [PubMed: 25791513]

29. Heijnsdijk EA, Wever EM, Auvinen A, et al. Quality-of-life effects of prostate-specific antigen screening. N Engl J Med. 2012;367(7):595-605. [PubMed: 22894572]

30. Loeb S, Vellekoop A, Ahmed HU, et al. Systematic review of complications of prostate biopsy. European urology. 2013;64(6):876-892. [PubMed: 23787356]

31. Loeb S, Bjurlin MA, Nicholson J, et al. Overdiagnosis and overtreatment of prostate cancer. European urology. 2014;65(6):1046-1055. [PubMed: 24439788]

32. Draisma G, Etzioni R, Tsodikov A, et al. Lead time and overdiagnosis in prostate-specific antigen screening: importance of methods and context. J Natl Cancer Inst. 2009;101(6):374-383. [PubMed: 19276453]

33. Welch HG, Kramer BS, Black WC. Epidemiologic Signatures in Cancer. The New England journal of medicine. 2019;381(14):1378-1386. [PubMed: 31577882]

34. Klotz L. Active surveillance for low-risk prostate cancer. Current opinion in urology. 2017;27(3):225-230. [PubMed: 28267056]

35. Bellardita L, Villa S, Valdagni R. Living with untreated prostate cancer: predictors of quality of life. Current opinion in urology. 2014;24(3):311-317. [PubMed: 24637318] 
36. McIntosh M, Opozda MJ, Evans H, et al. A systematic review of the unmet supportive care needs of men on active surveillance for prostate cancer. Psycho-oncology. 2019;28(12):2307-2322. [PubMed: 31663180]

37. Hoffman KE, Penson DF, Zhao Z, et al. Patient-Reported Outcomes Through 5 Years for Active Surveillance, Surgery, Brachytherapy, or External Beam Radiation With or Without Androgen Deprivation Therapy for Localized Prostate Cancer. Jama. 2020;323(2):149-163. [PubMed: 31935027]

38. Cooperberg MR, Carroll PR. Trends in Management for Patients With Localized Prostate Cancer, 1990-2013. JAMA. 2015;314(1):80-82. [PubMed: 26151271]

39. Loeb S, Byrne NK, Wang B, et al. Exploring Variation in the Use of Conservative Management for Low-risk Prostate Cancer in the Veterans Affairs Healthcare System. European urology. 2020.

40. Mottet N, Cornford P, van den Bergh R, et al. EAU-EANM-ESTRO-ESUR-SIOG Guidelines on Prostate Cancer 2020. Available at: https://uroweb.org/guideline/prostate-cancer/. 2020.

41. Johansson E, Steineck G, Holmberg L, et al. Long-term quality-of-life outcomes after radical prostatectomy or watchful waiting: the Scandinavian Prostate Cancer Group-4 randomised trial. The Lancet Oncology. 2011;12(9):891-899. [PubMed: 21821474]

42. Vickers AJ, Eastham JA, Scardino PT, Lilja H. The Memorial Sloan Kettering Cancer Center Recommendations for Prostate Cancer Screening. Urology. 2016.

43. Vickers A, Carlsson S, Laudone V, Lilja H. It ain't what you do, it's the way you do it: five golden rules for transforming prostate-specific antigen screening. European urology. 2014;66(2):188-190. [PubMed: 24411991]

44. Feng B, Srinivasan M, Hoffman JR, et al. Physician communication regarding prostate cancer screening: analysis of unannounced standardized patient visits. Annals of family medicine. 2013;11(4):315-323. [PubMed: 23835817]

45. Vickers AJ, Edwards K, Cooperberg MR, Mushlin AI. A simple schema for informed decision making about prostate cancer screening. Annals of internal medicine. 2014;161(6):441-442. [PubMed: 25222389]

46. Schumacher FR, Al Olama AA, Berndt SI, et al. Association analyses of more than 140,000 men identify 63 new prostate cancer susceptibility loci. Nat Genet. 2018;50(7):928-936. [PubMed: 29892016]

47. Aly M, Wiklund F, Xu J, et al. Polygenic risk score improves prostate cancer risk prediction: results from the Stockholm-1 cohort study. European urology. 2011;60(1):21-28. [PubMed: 21295399]

48. Pashayan N, Duffy SW, Neal DE, et al. Implications of polygenic risk-stratified screening for prostate cancer on overdiagnosis. Genet Med. 2015;17(10):789-795. [PubMed: 25569441]

49. Li-Sheng Chen S, Ching-Yuan Fann J, Sipeky C, et al. Risk Prediction of Prostate Cancer with Single Nucleotide Polymorphisms and Prostate Specific Antigen. The Journal of urology. 2019;201(3):486-495. [PubMed: 30366021]

50. Vickers AJ, Sjoberg DD, Ulmert D, et al. Empirical estimates of prostate cancer overdiagnosis by age and prostate-specific antigen. BMC Med. 2014;12:26. [PubMed: 24512643]

51. Schroder FH, Hugosson J, Roobol MJ, et al. Prostate-cancer mortality at 11 years of follow-up. The New England journal of medicine. 2012;366(11):981-990. [PubMed: 22417251]

52. Carlsson SV, Eastham JA, Crawford ED, Harris RG. "PSA Surveillance in the Septuagenarian": A Proposed New Terminology for Clinical Follow-up to Assess Risk of Prostate Cancer in Men Aged 70 Years and Older. European urology. 2020.

53. Vertosick EA, Poon BY, Vickers AJ. Relative value of race, family history and prostate specific antigen as indications for early initiation of prostate cancer screening. The Journal of urology. 2014;192(3):724-728. [PubMed: 24641912]

54. Carlsson S, Assel M, Sjoberg D, et al. Influence of blood prostate specific antigen levels at age 60 on benefits and harms of prostate cancer screening: population based cohort study. BMJ (Clinical research ed). 2014;348:g2296.

55. Eastham JA, Riedel E, Scardino PT, et al. Variation of serum prostate-specific antigen levels: an evaluation of year-to-year fluctuations. Jama. 2003;289(20):2695-2700. [PubMed: 12771116] 
56. Kearns JT, Lin DW. Improving the Specificity of PSA Screening with Serum and Urine Markers. Current urology reports. 2018;19(10):80. [PubMed: 30105509]

57. Kasivisvanathan V, Rannikko AS, Borghi M, et al. MRI-Targeted or Standard Biopsy for ProstateCancer Diagnosis. The New England journal of medicine. 2018;378(19):1767-1777. [PubMed: 29552975]

58. Drost FH, Osses D, Nieboer D, et al. Prostate Magnetic Resonance Imaging, with or Without Magnetic Resonance Imaging-targeted Biopsy, and Systematic Biopsy for Detecting Prostate Cancer: A Cochrane Systematic Review and Meta-analysis. European urology. 2020;77(1):78-94. [PubMed: 31326219]

59. Loppenberg B, Friedlander DF, Krasnova A, et al. Variation in the use of active surveillance for low-risk prostate cancer. Cancer. 2018;124(1):55-64. [PubMed: 28902401]

60. Eastham JA. Do high-volume hospitals and surgeons provide better care in urologic oncology? Urologic oncology. 2009;27(4):417-421. [PubMed: 19573772]

61. Savage CJ, Vickers AJ. Low annual caseloads of United States surgeons conducting radical prostatectomy. The Journal of urology. 2009;182(6):2677-2679. [PubMed: 19836787]

62. Vickers AJ, Savage CJ, Hruza M, et al. The surgical learning curve for laparoscopic radical prostatectomy: a retrospective cohort study. The Lancet Oncology. 2009;10(5):475-480. [PubMed: 19342300]

63. Bravi CA, Tin A, Vertosick E, et al. The Impact of Experience on the Risk of Surgical Margins and Biochemical Recurrence after Robot-Assisted Radical Prostatectomy: A Learning Curve Study. The Journal of urology. 2019;202(1):108-113. [PubMed: 30747873]

64. Vickers AJ, Bianco FJ, Serio AM, et al. The surgical learning curve for prostate cancer control after radical prostatectomy. Journal of the National Cancer Institute. 2007;99(15):1171-1177. [PubMed: 17652279]

65. Carroll P, Kellogg Parsons J, Andriole G, Bahnson RR, Carlsson S, Castle EP. NCCN Clinical Practice Guidelines in Oncology (NCCN Guidelines). Prostate Cancer Early Detection. V.2.2019. Available at: https://www.nccn.org/professionals/physician_gls/pdf/prostate_detection.pdf. 2019.

66. Carter HB, Albertsen PC, Barry MJ, et al. Early detection of prostate cancer: AUA Guideline. The Journal of urology. 2013;190(2):419-426. [PubMed: 23659877]

67. Force USPST, Grossman DC, Curry SJ, et al. Screening for Prostate Cancer: US Preventive Services Task Force Recommendation Statement. Jama. 2018;319(18):1901-1913. [PubMed: 29801017]

68. Wolf AMD, Wender RC, Etzioni RB, et al. American Cancer Society Guideline for the Early Detection of Prostate Cancer Update 2010. Ca-a Cancer Journal for Clinicians. 2010;60(2):70-98. [PubMed: 20200110]

69. Filella X, Albaladejo MD, Allue JA, et al. Prostate cancer screening: guidelines review and laboratory issues. Clin Chem Lab Med. 2019;57(10):1474-1487. [PubMed: 31120856]

70. Kohestani K, Chilov M, Carlsson SV. Prostate cancer screening-when to start and how to screen? Transl Androl Urol. 2018;7(1):34-45. [PubMed: 29594018]

Med Clin North Am. Author manuscript; available in PMC 2021 November 01. 


\section{Synopsis}

This paper gives an overview of the current state of the evidence for prostate cancer screening and early detection and summarizes current recommendations from guideline groups. The paper reviews the global public health burden and risk factors for prostate cancer with clinical implications as screening tools. Screening studies, novel biomarkers and magnetic resonance imaging are discussed. The paper outlines 7 key practice points for primary care physicians and provides a simple schema for facilitating shared decision-making conversations. 


\section{Key points}

- $\quad$ Prostate-specific antigen (PSA) screening can reduce the risk of metastatic prostate cancer and death from the disease but is also associated with major harms, including overdiagnosis and overtreatment, with concomitant urinary, sexual and bowel dysfunction.

- $\quad$ Primary care physicians can follow 7 simple steps that will dramatically reduce the harms of PSA screening while preserving its benefits.

- Patients need to be informed of the need for conservative management of lowgrade prostate cancer and referred to urologists who promote active surveillance.

- $\quad$ Primary care physicians need to develop relationships with urologists who advocate conservative approaches to biopsy and treatment. 
1. Get consent for prostate cancer screening, preferably using the "Simple Schema" decision aid.

2. PSA screening is only for healthy men age 45 to 70.

3. Tailor screening frequency based on PSA-level and cease screening for men over 60 unless PSA is above median $(1 \mathrm{ng} / \mathrm{mL})$.

4. For men with elevated PSA ( $\geq 3 \mathrm{ng} / \mathrm{mL}$ ), repeat PSA.

5. Use secondary tests such as marker or imaging before biopsy or only refer to urologists who do so.

6. Only refer to urologists who recommend active surveillance to almost all patients with low-grade cancer.

7. Preferably refer to urologists at major academic centers.

Figure 1.

Key practice points for primary care physicians 
Key facts about prostate cancer and screening

- Prostate cancer is common: most men will develop it if they live long enough.

- Although only a small proportion of men with prostate cancer die of the disease, the best evidence shows that screening reduces the risk for prostate cancer death.

- Screening detects many low-risk or "indolent" cancer cases.

- In the United States, most low-risk cancer is treated and the treatment itself can lead to complications, such as incontinence, erectile dysfunction, and bowel problems.

Key take-home messages

- The goal of screening is to find aggressive prostate cancer early and cure it before it spreads beyond the prostate.

- Most cancer cases found by screening do not need to be treated and can be safely managed by a program of careful monitoring known as "active surveillance."

- If you choose to be screened, there is a good chance that you will be diagnosed with low-risk cancer and you may face pressure from your physicians or family to treat it.

\section{Discrete decision}

- If you are concerned that you would be uncomfortable knowing that you have cancer and not treating it, screening may not be for you.

- If you are confident that you would only accept treatment for aggressive cancer and would not be unduly worried about living with a diagnosis of lowrisk disease, you are probably a good candidate for screening.

\section{Figure 2.}

Decision aid for primary care physicians for shared decision making about prostate cancer screening - the "Simple Schema"45

Reproduced with permission from Vickers AJ, Edwards K, Cooperberg MR, Mushlin AI. A simple schema for informed decision making about prostate cancer screening. Annals of Internal Medicine. 2014;161:441-442. https://www.acpjournals.org/doi/10.7326/M14-0151 
Table 1.

Examples of current guidelines for prostate cancer screening in 2020. Data from Refs 69,70

\begin{tabular}{|c|c|c|c|c|}
\hline Guideline group & Year & Reference & Age to start & Age to stop \\
\hline $\begin{array}{l}\text { National Comprehensive Cancer Network } \\
(\mathrm{NCCN})\end{array}$ & 2019 & 65 & $40-45$ & 75 (continue in select cases) \\
\hline $\begin{array}{l}\text { Memorial Sloan Kettering Cancer Center } \\
\text { (MSK) }\end{array}$ & 2016 & 42 & 45 & $\begin{array}{l}60 \text { for men with PSA }<1 \mathrm{ng} / \mathrm{mL} \\
\text { otherwise } 70 \text { (continue based on } \\
\text { general health and prior PSAs) }\end{array}$ \\
\hline $\begin{array}{l}\text { European Association of Urology (EAU) - } \\
\text { European Association of Nuclear Medicine } \\
\text { (EANM) - European Society for Radiotherapy } \\
\text { \& Oncology (ESTRO) - European Society of } \\
\text { Urogenital Radiology (ESUR) -International } \\
\text { Society of Geriatric Oncology (SIOG) }\end{array}$ & 2020 & 40 & $\begin{array}{l}50 \\
45 \text { if family history or } \\
\text { African-American } \\
40 \text { if carrying BRCA2 } \\
\text { mutations }\end{array}$ & $\begin{array}{l}<15 \text { years life expectancy (stop based } \\
\text { on life expectancy and performance } \\
\text { status) }\end{array}$ \\
\hline American Urological Association (AUA) & $2013^{*}$ & 66 & 55 & 70 (or $<10-15$ years life expectancy) \\
\hline $\begin{array}{l}\text { United States Preventive Services Task Force } \\
\text { (USPSTF) }\end{array}$ & 2018 & 67 & $\begin{array}{l}55 \text { (shared decision } \\
\text { making) }\end{array}$ & 70 (recommends against) \\
\hline American Cancer Society (ACS) & 2010 & 68 & $\begin{array}{l}50 \text { (shared decision } \\
\text { making) }\end{array}$ & $<10$ years life expectancy \\
\hline
\end{tabular}

For additional examples of recommendations for PSA screening from various guideline groups, please see recent comprehensive reviews.

Published 2013; Reviewed and validity confirmed 2018. 
Table 2.

Reflex biomarkers recommended by the National Comprehensive Cancer Network (NCCN) Guidelines v.2.2019 Prostate Cancer Early Detection. From Carroll P, Kellogg Parsons J, Andriole G, et al. NCCN Clinical Practice Guidelines in Oncology (NCCN Guidelines). Prostate Cancer Early Detection. V.2.2019. Available at: https://www.nccn.org/professionals/physician_gls/pdf/prostate_detection.pdf. 2019. With permisison

\begin{tabular}{|l|l|}
\hline Initial biopsy & Repeat biopsy \\
\hline$\%$ free PSA & $\%$ free PSA \\
\hline Prostate Health Index (PHI) & Prostate Health Index (PHI) \\
\hline 4 Kscore & 4 Kscore \\
\hline ExoDx Prostate (IntelliScore) & ExoDx Prostate (IntelliScore) \\
\hline & PCA3 \\
\hline & ConfirmMDx \\
\hline
\end{tabular}

Additional biomarkers (investigational): Michigan Prostate Score (MiPS), SelectMDx 